\title{
Emerging Fashion Trends for Autumn Winter Season
}

\author{
Muhukumar Nair* \\ [Director-Vidya Institute of Fashion Technology, U.P. Technical University, Lucknow, India ]
}

\begin{abstract}
This study was describe the values of trends and its need for the designers. Another purpose of the study to identify the duration of demands for the particular design/style. Thus the market value automatically high during the trend season and the merchandising process would across the break even point.
\end{abstract}

Keywords : Color, Material, Market, Season, Stipulation.

\section{Introduction}

It's time to wrap up warm for autumn and winter, but there's no need to stop looking fabulous. Fashion trends this winter will let you retain a bit of glam - while also staying warm - and with versatility there's something to suit all styles and body shapes.

Fashion trends change frequently keeping retail professionals on their toes. One of the most anticipated fashion trends involves the most popular colors which shift from season to season. Each year Pantone announces its top color often inspiring clothing and accessory designs for winter season, Pantone's top color is emerald green, and the color showed up consistently on the fall and winter runway shows indicating that it will be a mainstay of winter fashion.

"During the cold and dark of Arctic winter, sea ice refreezes and achieves its maximum extent, usually in late Feb. or early Mar. According to a NASA analysis, this year the annual maximum extent was reached on Feb. 28 and it was the fifth lowest sea ice winter extent in the past 35 years."

NASA / Goddard Space Flight Center "ScienceDaily, 3 April 2013

"As winter approaches, many of us hunker down and virtually "hibernate" for the season. Classic hibernation in the wild conjures images of furry bears, but other animals are not so lucky to have immense fat stores or fur to protect them from the elements."

By Dr.Don Larson (Society for Integrative and Comparative Biology (SICB), January 6, 2014)

"Professor and chair of the Department of Design and Computation Arts at Concordia, has developed interactive electronic fabrics that harness power directly from the human body, store that energy, and then use it to change the garments' visual properties."

"Our goal is to create garments that can transform in complex and surprising ways - far beyond reversible jackets, or shirts that change colour in response to heat. That's why the project is called Karma Chameleon,"

By Berzowska.( DCA, Concordia University, April 17 ,2013)

\section{Warm materials}

Leather pieces which are wardrobe classics continue to be a popular option for the fall and winter 2013 fashion lines. Instead of traditional black or brown leather however the 2013 fall fashion trends include pieces in bright jewel tones. Leather transcends age boundaries leather skirts are ideal investments.

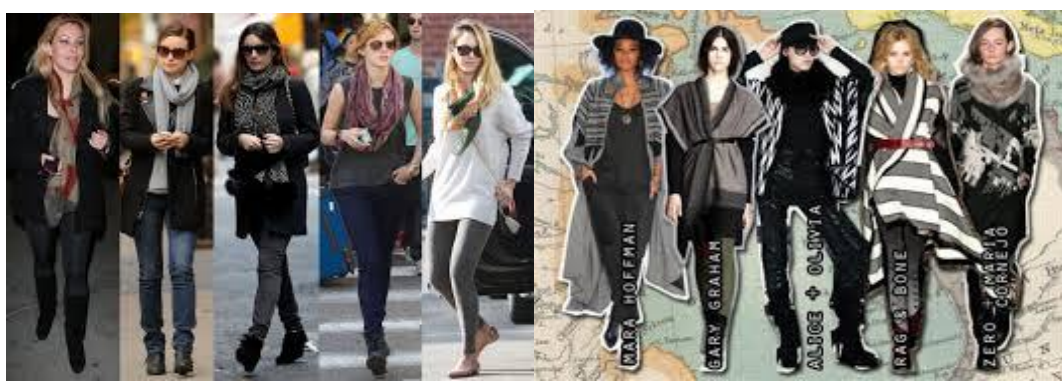


As the temperatures drop, consumers are ditching their sandals and strappy heels and reaching for warmer boots. The bootie trend of 2012 continues into 2013-14, giving fashion followers the option to carry their older footwear into the new season.

The latest bootie styles, however feature buckles and other embellishments. They can be worn with skirts, dresses, and pants, making them a practical part of winter fashion. Booties for 2013 are available in both flat and heeled styles that are compatible with other fashion trends.

Whether your business caters to young trendy customers or older, sophisticated clientele, leather pieces are sure to be big sellers. The patent leather bag will be around this winter - in glamorous black, bold purple or charcoal grey. Oversize and clutch bags remain amongst the top picks for fashion-conscious women this winter.

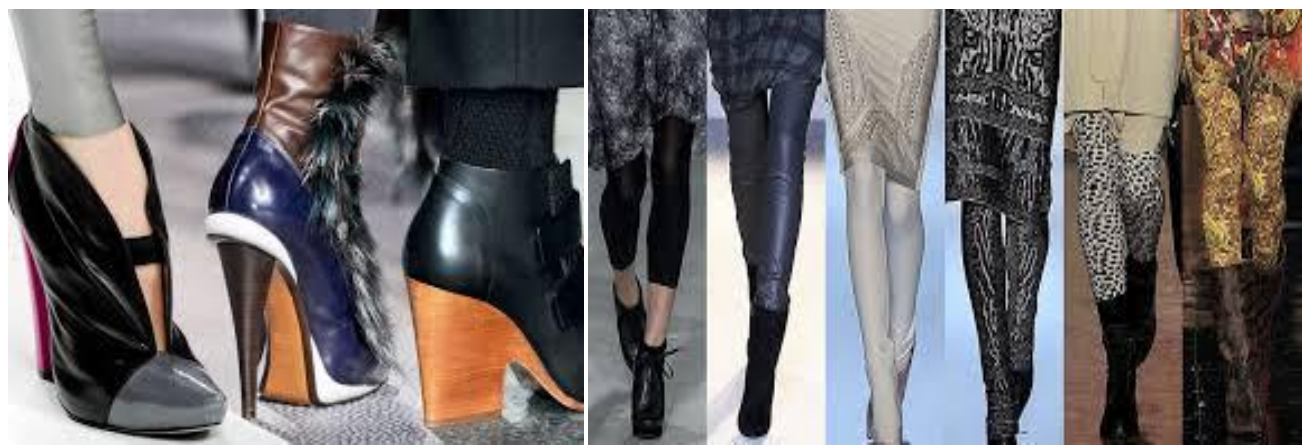

A high heel is in vogue for the winter months, giving you a simmer look even on the coldest night. Watch for styles in patent leather (to match your bag), metallic hues (if full metallic is too much, you'll find them with gold or silver detail too) and bright colours (shoes in red, blue or green are great with dark outfits). For boots this winter, ankle boots are taking a leap up the popularity stakes - slouchy, simple, suede or leather. These look superb with tights and a skirt.

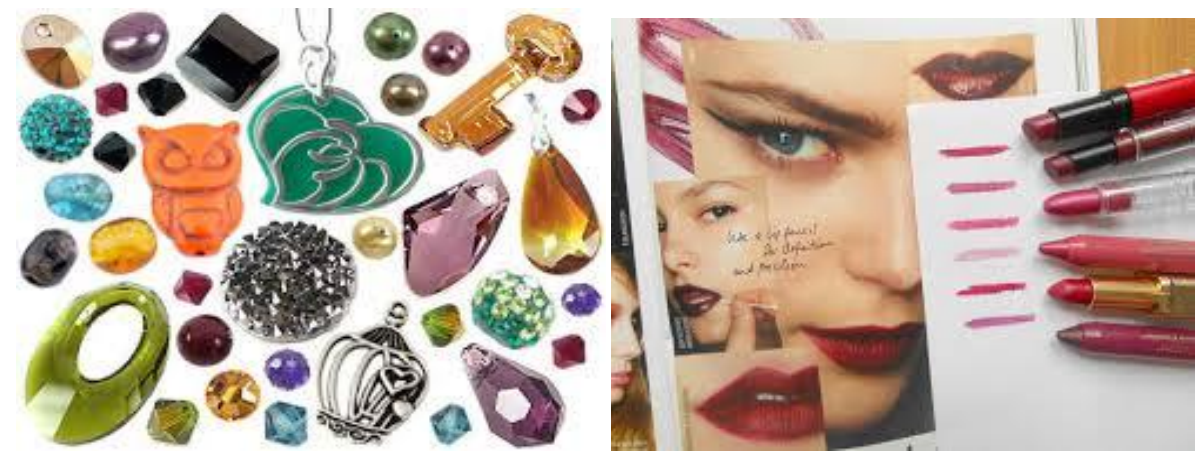

\section{Conclusion}

The trends would be the major role to launch the products in the Market within the stipulated season. This is the guide line for the consumers and manufactures too.

\section{Reference}

[1]. 1.NASA / Goddard Space Flight Center "ScienceDaily, 3 April 2013.

[2]. 2.Dr.Don Larson (Society for Integrative and Comparative Biology (SICB), January 6, 2014).

[3]. 3.Prof. Berzowska.( Design and Computing Art, Concordia University, April 17, 2013). 